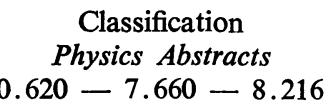

\title{
A NEW METHOD OF MEASURING THE THERMOELECTRIC FIGURE OF MERIT (*)
}

\author{
G. PEGNA and A. CONGIU \\ Istituto di Fisica, Università di Cagliari, Italie \\ (Reçu le 17 octobre, révisé le 13 janvier 1975)
}

\begin{abstract}
Résumé. - On décrit ici une nouvelle méthode expérimentale pour la détermination de la figure de mérite des solides semiconducteurs. Cette méthode permit une rapide classification des propriétés thermo-électriques des nouveaux matériaux.
\end{abstract}

\begin{abstract}
A new experimental method for the determination of the figure of merit of semiconductors is described. This method allows a fast classification of the thermoelectric properties of new materials.
\end{abstract}

In this note we propose, besides the methods reported in the literature [1, 2], a new experimental procedure for measuring the thermoelectric figure of merit (T. F. M.) $Z$ of a semiconducting material, which has the advantage of being relatively simple and speedy, although not as accurate as others. This method is routinely used in our laboratory for a gross evaluation of the T.F.M. of new semiconducting ternary and quaternary compounds $[3,4]$.

The measurements are performed by a variable temperature cryostat such as described by Klein et al. [5], which allows a steady heat flow $Q / t$ along the main axis of the rod-shaped samples. The sample holder is made in such a way as to allow the measurement of the thermal gradient between the ends of the sample, to which two electric contacts are also applied.

The T. F. M. is defined by :

$$
Z=\frac{a^{2} \sigma}{K}
$$

where $a$ is the thermoelectric power, $\sigma$ the electrical conductivity and $K$ the thermal conductivity : $K=Q . l / \Delta T$.S.t $(l$ and $S$ are the length and the cross section of the sample).

The idea is to apply a steady heat flow $Q / t$ through the sample and to measure : (i) the resulting thermoelectric e. m. f. $V_{\mathrm{T}}$; (ii) the intensity $I$ of the current which flows when the circuit is closed on a microammeter(Fig. 1). From these measurements we can compute $\sigma$ and consequently $Z$.

(*) Work supported by C. N. R. through G. N, S. M.
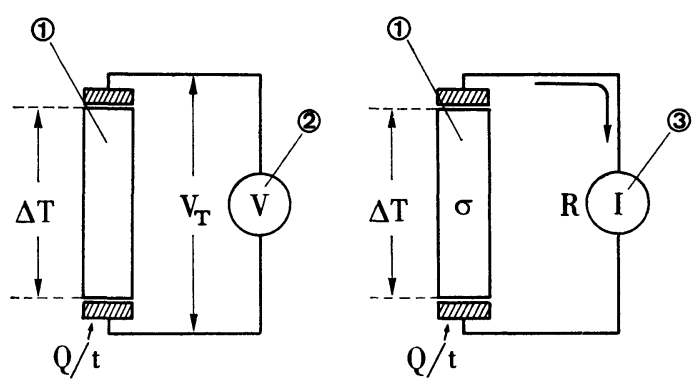

FIG. 1. - Schematic drawing of measurement steps (i) and (ii). (1) Sample. (2) Microvoltmeter. (3) Microammeter.

Let us define :

$$
R_{\mathrm{tot}}=\frac{l}{\sigma . S}+R
$$

and :

$$
I=\frac{V_{\mathrm{T}}}{R_{\mathrm{tot}}}=\frac{V_{\mathrm{T}}}{l / \sigma S+R}
$$

where $l / \sigma S$ is the resistance of the sample, $R$ the input resistance of the microammeter, and $I$ the intensity of the current in the closed circuit. From eq. (1) and (3), and also from $a=V_{\mathrm{T}} / \Delta T$, we obtain

$$
Z=\frac{V_{\mathrm{T}}^{2} I}{\Delta T \cdot Q / t\left(V_{\mathrm{T}}-R I\right)} .
$$

Now, if the voltage drop R.I at the microammeter input is negligible with respect to $V_{\mathrm{T}}$, we have the final expression :

$$
Z=\frac{V_{\mathrm{T}} \cdot I}{W \cdot \Delta T}
$$


in which the heat flow has been replaced by the electric heat power $W$ of the heater. If the heat dispersions are sufficiently low, these quantities coincide.

The $V_{\mathrm{T}}$ and $I$ values are measured by means of the same universal electronic multimeter $\left({ }^{1}\right)$ in rapid succession ; $\Delta T$ is constantly monitored on a separate instrument ; $W$ is a known parameter.

In discussing the accuracy of this method, we may observe that the measurements are still sufficiently accurate (i) if the sample resistance is at least 5 to 10 times larger than the input resistance $R$ of the ammeter, as can be seen from eq. (4) ; and (ii) if it is possible to make sufficiently good electrical and thermal contacts to the sample.

For a $10 \%$ precision in the measurements, eq. (4) gives :

$$
V_{\mathrm{T}}>10 R I
$$

and the input characteristics of the microammeter used give the limiting conditions for the parameters to be measured. In our case, for the Keithley model $150 \mathrm{~B}$, since the input resistance in the $\mu \mathrm{A}$ ranges is: $R=10^{-3} /$ Range (in A), we must have $V_{\mathrm{T}}>10 \mathrm{mV}$. This can always be obtained by regulating the electric

(1) Keithley model 150 B, for example. heating power $W$, in order to develop a sufficiently large temperature gradient $\Delta T$.

The thermal conductivity in turn determines the heating power needed to realise an acceptable value for $\Delta T$. Extremely wide ranges for this parameter are acceptable, the only limitations being the thermal power of the constant temperature control system.

For our samples $[3,4] \Delta T$ is of the order of a few ${ }^{\circ} \mathrm{C}$, and can be obtained with a heating power $W$ of about $1 \mathrm{~W}$.

In these conditions the resistance $R_{\mathrm{s}}$ of the sample must be :

$$
R_{\mathrm{s}}>10 R
$$

so follows that minimum acceptable values for $R_{\mathrm{s}}$ are actually about $10^{2}-10^{3} \Omega$.

On the other hand, the maximum sensitivity of the microammeter limits the maximum values of the resistance of the sample. For the Keithley model $150 \mathrm{~B}$, $R I=100 \mu \mathrm{V}$ in the $0.3 \mathrm{nA}$ range, so that, since $V_{\mathrm{T}}$, in these ranges, must be greater than $1 \mathrm{mV}, R_{\mathrm{s}}$ should not be greater than some $10^{6} \Omega$.

Note. - Eq. (5) clarifies also the physical meaning of the T.F. M. : is is the ratio between the electric power thermoelectrically generated by the sample, and the electrical heating power $W$, referred to a unity temperature difference between the ends of the rod.

\section{References}

[1] IofFe, A. F., « Semiconductor Thermoelements and Thermoelectric Cooling », Infosearch Ltd, London 1957.

[2] Harman, T. C., Cahn, J. H. and Logan, M. J., J. Appl. Phys. 30 (1959) 1351.

[3] Congiu, A., Garbato, L. and Serci, S., Phys. Stat. Sol. (a), 5 (1971) K 15
[4] Congiu, A., Garbato, L., Manca, P. and Serci, S., J. Electrochem. Soc. 119 (1972) 280.

[5] Klein, M. V. and Caldwell, R. F., Rev. Sci. Instrum. 37 (1966) 1921. 